\title{
Temporal Variation Analyses of Suspended Sediment Load in an Agricultural Catchment and its Land Use Implications
}

\author{
Masayaki Fujihara ${ }^{1}$, Edward Lapong ${ }^{2}$, Tomoki Izumi ${ }^{3}$ and Noriyuki Kobayashi ${ }^{3}$
}

\author{
${ }^{1}$ Water Resources Engineering Laboratory, Division of Environmental Science and Technology \\ Graduate School of Agriculture, Kyoto University \\ ${ }^{2}$ Department of Agricultural Engineering, College of Agriculture, Mindanao State University-General \\ Santos, Philippines (Corresponding author: edwardlapong@yahoo.com) \\ ${ }^{3}$ Faculty of Agriculture, Ehime University, Matsuyama, Ehime, Japan
}

Received: July 31, 2017; Accepted: December 5, 2017

\begin{abstract}
The suspended sediment load of a small agricultural river was estimated using suspended sediment rating curves established using discharge-suspended sediment discharge correlation and stratified aggregate or seasonally clustered data; and the results were correlated to the land use of the watershed. The results showed that: (a) on regression, nonlinear least squares method in establishing rating curves produced significantly better and more efficient suspended sediment rating curves; (b) seasonally clustering the data produced better suspended sediment rating curves; (c) based on statistical and physical relations, suspended sediment load in the catchment followed a clear cyclical seasonal pattern; and (d) the land use and agricultural activities, other than rainfall, had a significant impact on the temporal distribution and variability of the suspended sediment load.
\end{abstract}

Keywords: suspended sediment, sediment rating curve and load estimation, agricultural catchment

The temporal and spatial variability of sediment within the drainage basin is a key issue on river basin studies. Specifically, sediment transport and its downstream implications are of increasing interest for water quality and land use management. Information about sediment loads is useful for the evaluation of sediment yield erosion rates, water quality trends, ecological impacts, sediment dynamics during floods; and to assess downstream geomorphic effects (Batalla and Sala, 1994; Ferguson, 1986; De Vries and Klavers, 1994). Moreover, suspended sediment information is important in detecting change of land use and impact of land use management.

Agricultural activities caused much of the accelerated erosion due to unfavourable and poor tillage practices, resulting to influx from both point and non-point sources (Walling and Webb, 1992; Meybeck et al., 1996). Although its effects are usually seen as less dramatic, the impact of suspended sediment is great and with huge valuated economic damage. Especially in areas with seasonal agricultural activities, suspended sediment is rather seen as less of a problem and considered as just an ordinary result of cultivation. However, closer scrutiny may find its impact as significant, especially to a relatively clean draining river.

There are several approaches in the estimation of river suspended sediment. This can be summarized into three main categories: basin scale erosion model approach (Mendicino, 1999; Iadanza and Napolitano, 2006), theoretical approach (Maidment, 1992) and empirical approach (Jansson, 1992; Cordova and Gonzalez, 1997; Lenzi and Marchi, 2000; Achite and Ouillon, 2007; Sadeghi et al., 2008). The basin scale erosion models proved to be tedious and the uncertainty in determining the sediment delivery ratio made it less likely to be used in sediment yield. More so, theoretical models require adequate knowledge of hydraulics and hydrodynamic and requires extensive validation (Shanahan et al., 1998). This leaves the 
empirical approach as the most readily available method and, in fact, more accurate in estimating sediment yield.

With the empirical approach, researchers typically estimate total sediment loads from a series of statistical techniques (e.g. rating curves, interpolation) developed based on discrete sampling. Most quantitative studies of suspended sediment load using empirical approach used suspended sediment rating curve derived from dischargesuspended sediment concentration (Q-SC) relationship by least-square methods after logarithmic transformation of the data or by directly derivation using non-linear regression in the form, $S C=a Q^{b}$ (Fergusson, 1986, Hasnain, 1996, Jansson, 1996). This may sometimes not be applicable due to high scatter of data and the consequent poor correlation between $\mathrm{Q}$ and $\mathrm{SC}$, nor to rivers with wide range of SC (Horowitz, 2003). This limitation, however, may be ameliorated by the use of dischargesuspended sediment discharge (Q-SD) relationship (Restrepo and Kjerfve, 2000).

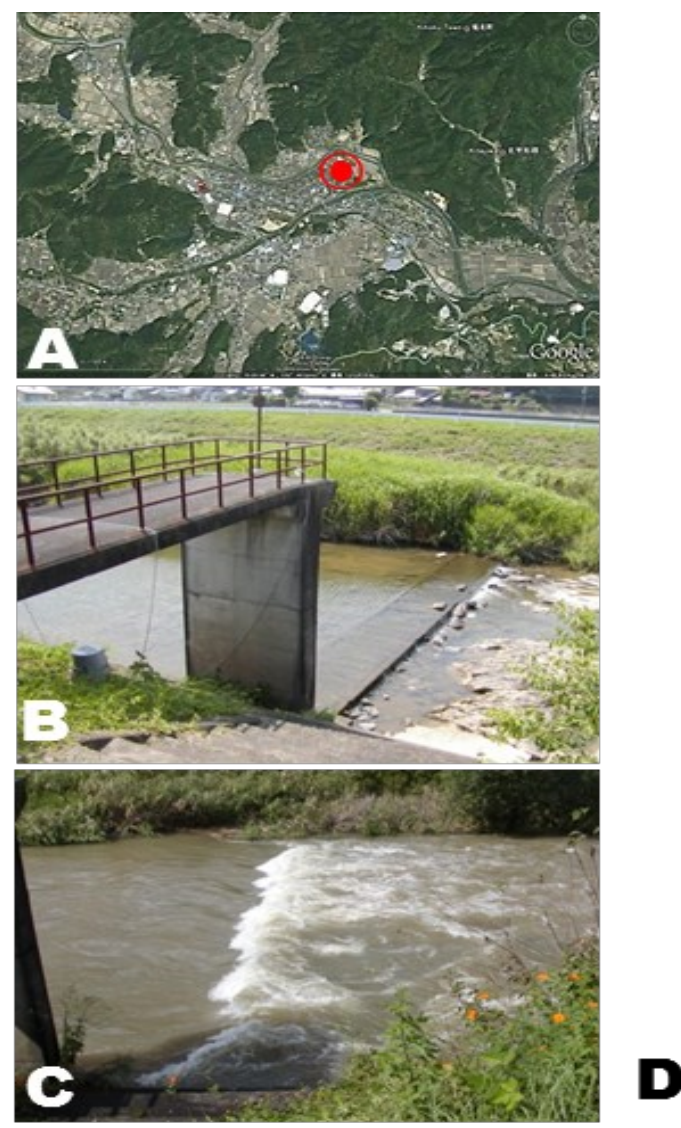

This paper presents a baseline monitoring and case analysis of suspended sediment transport in a small seasonally-cultivated agricultural catchment. It shows monthly and seasonal scales of suspended sediment distribution, determines the temporal differences in suspended sediment rating curves, and assesses the difference of linear and non-linear least square methods of regression analysis. Moreover, it introduces the use of data stratification to improve regression results and to adapt power function suspended sediment rating curve in small rivers with nil and highly variable suspended sediment concentration. Finally, the study aimed to correlate the present land use and seasonal agricultural cultivation in the area to the suspended sediment in the draining river.

\section{Study Area}

The study site is Mima River, draining an agricultural area located in southern Ehime Prefecture, Japan (Figure 1). It is located between latitudes $33^{\circ} 15.2^{\prime} \mathrm{N}$ and $33^{\circ} 19.8^{\prime} \mathrm{N}$, and between lon-
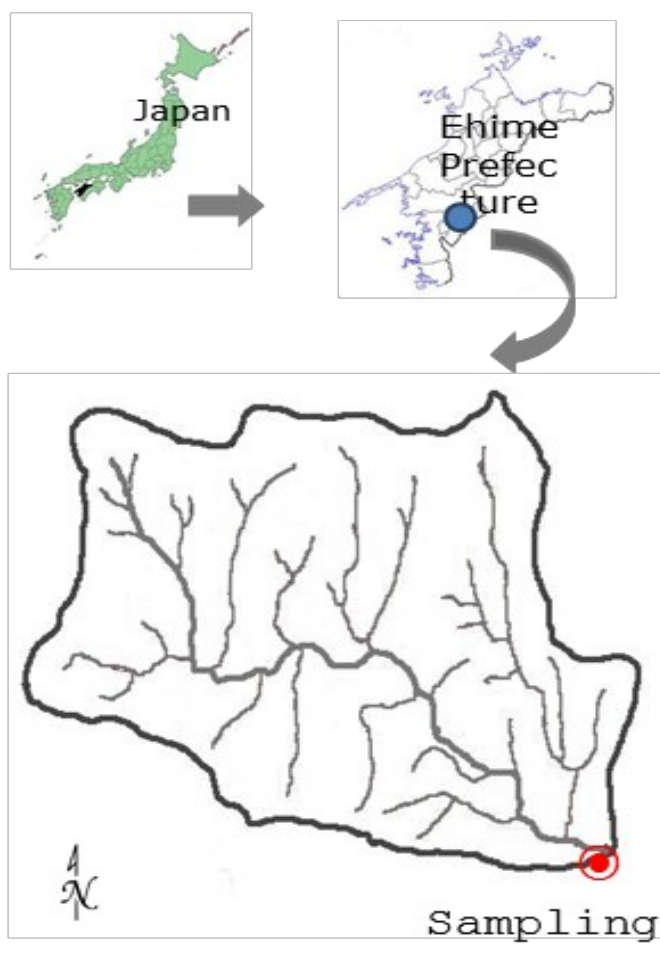

site

Figure 1. A. Study site relative location, B-C. sampling site, D. basin boundaries and stream network. 
gitudes $132^{\circ} 33.5^{\prime} \mathrm{E}$ and $132^{\circ} 41.4^{\prime} \mathrm{E}$. The Mima River flows into the bigger Hiromi River $\left(\right.$ Area $\left.=190 \mathrm{~km}^{2}\right)$, which in turn flows into the Shimanto River of the adjacent Kochi Prefecture. The Shimanto river is sometimes considered as the 'last clear stream of Japan' but, recently, its pristine waters is in danger of deterioration due to the sediment-laden inflows from its tributaries.

The Mima river catchment has an area of 73 $\mathrm{km}^{2}$, a main stream length of $17 \mathrm{~km}$, a $3^{\text {rd }}$ stream order according to the Strahler method, and is classified as 'small river' based on the river classification set by United Nations Environment Programme (UNEP) and World Health Organization (WHO). The farthest and highest tributary elevation in the catchment is 857 masl and the river mouth at 113 masl, thus, an average stream gradient of $0.010 \mathrm{~m} / \mathrm{m}$.

The catchment is basically forested $(69 \%)$ with only a small fraction of the area being arable. This is typical of any land in Japan where forest covers at least $65 \%$ of the total area (Sadeghi et al, 2008 ). Arable land constitutes only $11 \%$ of the total area, and the remaining are residential, grassland, and other land use areas $(15 \%)$. The arable land is generally apportioned to rice and vegetable production, with rice paddy field comprising at least $70 \%$, making it a significant land use. Rice production is the biggest agricultural activity, grown from April to September.

The area has an average annual rainfall of $1,995 \mathrm{~mm}$. The wettest period is June October, with a mean monthly rainfall of at least $250 \mathrm{~mm}$. The rainfall is highest during June and lowest during December. Rainfall season starts on June and typhoons occur during summer (June $\sim$ August) and early autumn (September Ocotber). The rice paddy preparation and rice seedling transplanting onto paddy fields are conducted from April until the beginning of June, but may start as early as middle of March in some areas. Among the activities, the soil paddling produces the most sediment as paddy fields are flooded during the operation. Then, highsediment waters are usually drained or at least partially-drained just before or during rice seedling transplanting.

\section{Materials and Methods}

\section{Data monitoring and Instrumentation}

We monitored the discharge and suspended sediment concentration of the Mima river from April 2008 to December 2011. The sampling site is located before a shallow weir at a considerable distance (approximately $1 \mathrm{~km}$ ) before its confluence with another river (Figure 1).

We collected $500 \mathrm{~mL}$ water samples by an ISCO Model 3700 Standard Portable Automatic Sampler with suction hose placed along a straight, well-mixed area few meters from the river bank, and at several centimeters above the river bed. Sampling frequency is twice a day (12-hr time step) during agricultural production season (AprilAugust) and once a day (24-hr time step) during other months. We set the sampling time 17:00 to capture any sediment occurrence during daytime and at 5:00, on a 12-hr time step, to capture occurrences during night time. The monitoring yields 1,443 data sets which are reduced to 1007 upon averaging the 12-hr time step data: spring (261), summer (284), fall (267), and winter (192).

This study adopted the filtration-oven method (APHA, 1995) for sediment analysis, using a 1.0$\mu \mathrm{m}$ pore diameter, Standard Whatman glass microfiber filters. A STS EN60079-14 stage data logger installed at the weirs was used to monitor the river water depth at 1-hr interval. We then computed the discharge using the developed rating curve in the form, $Q=a H^{b}$, where $Q$ is discharge, $H$ water depth, and $a, b$ constants. We took the rainfall data, concurrent with discharge data, from an Automated Meteorological Data Acquisition System located approximately $500 \mathrm{~m}$ from the sampling site.

\section{Analysis Procedure}

We analysed preliminarily the discharge and suspended sediment concentration data for statistical properties and trend characteristics. The area is characterized by four seasons, hence, data are clustered into months and seasons: spring (MarchMay), summer (June-August), fall (SeptemberNovember), and winter (December-February). Time series data classified into monthly and seasonal series were analysed as to cycles and hysteresis. Particularly, seasonal clusters show the effect of predominant factors-rainfall and agricultural activities - to the suspended sediment load temporal distribution.

We estimated the suspended sediment load by power regression analysis using river dischargesuspended sediment discharge correlation in the form, $S D=a Q^{b}$, where $S D$ is suspended sediment discharge, $a$ and $b$ are constants (Jansson, 1985; Thomas, 1985; Achite and Ouillon, 2007; Hu et al., 2011). The Mima river has a high Q-SC (dischargesediment concentration) scatter, hence, poor corre- 
lation and high error term in fitted regression. This Q-SC correlation characteristic was also found out in many relatively small catchments and even in big rivers. Based on the studies conducted by Jansson $(1992,1996)$, it is not easy to establish a single relationship between suspended sediment concentration and water discharge because of the differences in the level of concentration for high water events and of hysteresis relationship for each event. In such cases, $S D(=Q \times S C)$ could be adapted as the dependent regression factor and to describe sediment transport.

In the regression analysis, we compared the linear least squares (LLS) method (Cordova and Gonzalez, 1997; Iadanza and Napolitano, 2006) and non-linear least squares (NLLS) method (Jansson, 1996; Asselman, 2000; Hu et al., 2011) methods and we found the latter to produce suspended sediment rating curves with better fit and higher efficiency. Also, we introduced an amelioration procedure to account for the nil suspended sediment concentration values-data stratification or using mean values within discharge classes (Jansson, 1996). Moreover, we derived the temporal (monthly and seasonal) water yield and the corresponding suspended sediment yield using the established rating curves.

The efficiency of the derived rating curves in estimating the suspended load was evaluated based on the model efficiency criterion, $\boldsymbol{e}_{f}$, as defined by Nash and Sutcliffe (1970);

$$
e_{f}=1-\frac{\sum_{t=1}^{T}\left(S D_{o}^{t}-S D_{m}^{t}\right)^{2}}{\sum_{t=1}^{T}\left(S D_{o}^{t}-\overline{S D_{o}}\right)^{2}}
$$

where $e_{f}$ is Nash-Sutcliffe coefficient, $S D_{o}{ }^{t}$ and $S D_{m}{ }^{t}$ observed and modeled SD at time $t, \overline{S D}_{0}$ mean observed suspended sediment discharge. A statistical test (t-Test) was also performed to verify any significant difference among decision parameters. The XLStat software version 2011 was used to perform the analyses, i.e. regression, trend, and statistical (mean, median, mode, skewness, kurtosis, coefficient of variation).

\section{Results and Discussion}

\section{Discharge and Suspended Sediment Character- istics}

The discharge in the Mima river catchment generally follows the event, monthly, and seasonal patterns of precipitation (Figure 2). It is relatively high during the months of March, June-July and September-October which are characterized by high precipitation events and/or regular typhoon occurrences (Figure 3).

The monthly data of water yield shows a trimodal distribution with highest peak during June, while the seasonal trend comes in a cycle reaching peak during summer and gradually falling towards winter (Figure 3). The seasonal mean discharge complements the water yield temporal distribution. The discharge data distribution, considering aggregate and seasonal data, are highly skewed to the right (Skewness, $\mathrm{Sk}>0$ ) and have a very sharp peak (Kurtosis, Kurt $>0$ ), reflecting the effect of infrequent very high storm events. They have the high-

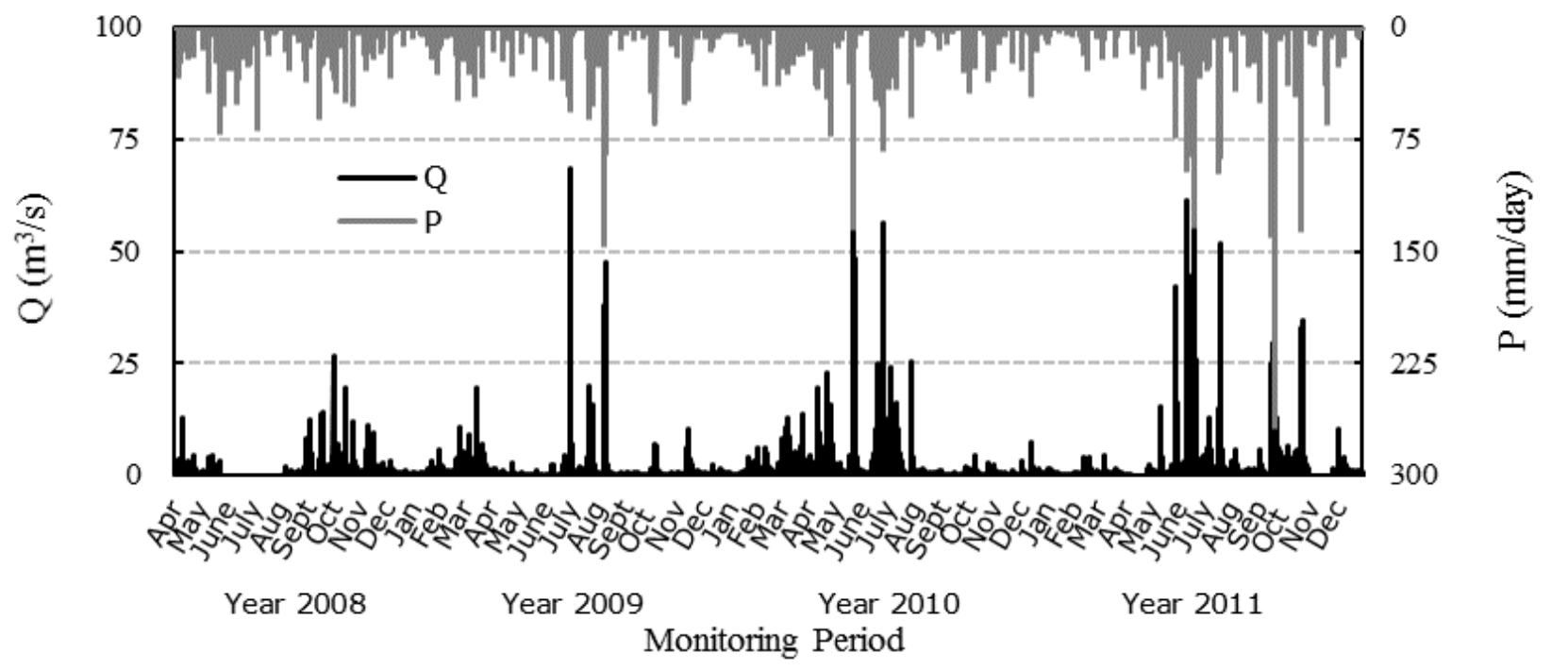

Figure 2. Daily discharge (Q) and precipitation (P) at Mima catchment. 


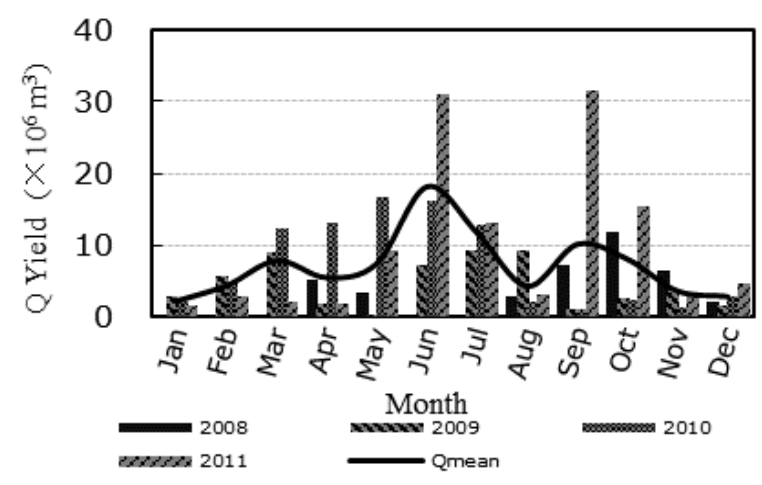

$[\mathrm{A}]$

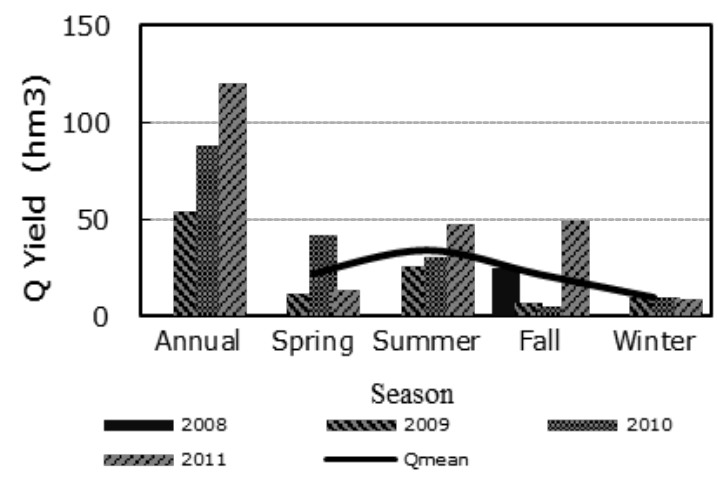

[B]

Figure 3. Monthly $[\mathrm{A}]$ and seasonal water yield $[\mathrm{B}]$ of Mima river.

est range, dispersion (CV), skewness, and peakedness during Spring (Table 1), although all seasons have also relatively high equivalent statistical characteristics due to largely low and few but extremely high peak discharge values.

A closer perusal of the time series data shows that suspended sediment concentration has irregular peaks unproportionate to that of discharge, especially during spring and summer seasons which correspond to the agricultural production season, particularly rice production (Figure 5). It apparently reflects the effect of agricultural activities, especially the drainage from rice paddy fields. Generally, SC did not follow the monthly and seasonal pat- terns of discharge (Figures 3 and 4).

The SC has a wide range of values, that is 0 395 mg/l, considering aggregate data (Table 1). Extremely high SC values were mostly recorded during Fall, particularly during September and October due to high storm events. The wide range translates to a high coefficient of variation $(\mathrm{CV})$, at $122 \%$, considering aggregate data. The $\mathrm{CV}$ values, however, are much lower compared to the CV values of big rivers as the latter's may vary up to three or five degrees of magnitude (Iadanza and Napolitano, 2006; Sadeghi et al, 2008; Hu et al, 2011). The SC data distribution is slightly skewed to the right (as shown by mean $>$ median) and slightly

Table 1. Statistical values of discharge, sediment concentration, and sediment discharge of Mima River.

\begin{tabular}{|c|c|c|c|c|c|c|c|c|}
\hline Data/Season & Min. & Median & Max. & Mean & CV $(\%)$ & Sk & Kurt & Sample Size \\
\hline $\mathrm{Q}\left(\mathrm{m}^{3} / \mathrm{s}\right):$ Aggregate & 0.07 & 0.77 & 93.5 & 2.1 & 278 & 8.0 & 105 & 1007 \\
\hline Spring & 0.10 & 0.79 & 93.5 & 2.4 & 320 & 8.2 & 91 & 261 \\
\hline Summer & 0.07 & 0.87 & 55.4 & 2.9 & 259 & 5.2 & 29 & 284 \\
\hline Fall & 0.10 & 0.58 & 43.3 & 1.7 & 186 & 5.2 & 35 & 267 \\
\hline Winter & 0.31 & 0.78 & 12.5 & 1.2 & 110 & 4.5 & 31 & 192 \\
\hline $\mathrm{SC}(m g / L)$ : Aggregate & 0 & 16 & 395 & 28 & 122 & 3.4 & 17 & 1007 \\
\hline Spring & 0 & 25 & 217 & 38 & 101 & 2.0 & 4 & 261 \\
\hline Summer & 1.7 & 18 & 167 & 28 & 93 & 2.2 & 7 & 284 \\
\hline Fall & 0 & 15 & 395 & 25 & 154 & 4.8 & 34 & 267 \\
\hline Winter & 0 & 7 & 143 & 15 & 139 & 2.8 & 10 & 192 \\
\hline $\mathrm{SD}(k g / h r)$ : Aggregate & 0 & 44 & 58468 & 370 & 728 & 16.6 & 316 & 1007 \\
\hline Spring & 0 & 65 & 58468 & 489 & 784 & 14.4 & 214 & 261 \\
\hline Summer & 1.5 & 61 & 16435 & 566 & 380 & 5.7 & 33 & 284 \\
\hline Fall & 0 & 37 & 42989 & 299 & 936 & 15.1 & 228 & 267 \\
\hline Winter & 0 & 25 & 2313 & 80 & 260 & 7.5 & 71 & 192 \\
\hline
\end{tabular}




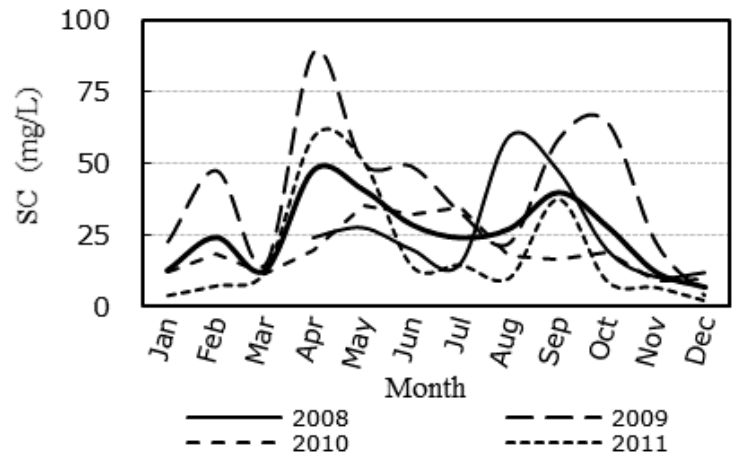

$[\mathrm{A}]$

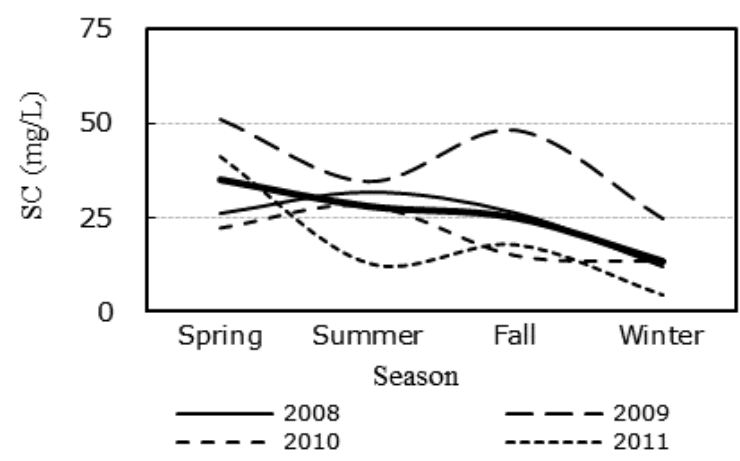

[B]

Figure 4. Mean monthly [A] and seasonal sediment concentration [B] of Mima river.

peaked as effected by many low to average and few extremely high values. In fact, approximately $80 \%$ of the SC values are below the mean.

Nil values accounted approximately $5 \%$ of the recorded SC values. The occurrence is highest during Winter ( $20 \%$ of the total seasonal data) which is a period of low and clear flow, as well as no agricultural activities. The occurrence of nil SC could be attributed to the fact that the Mima river is small and unlike big rivers which usually contain abundant suspended materials for transport, it often depend on episodic contribution from upland areas.

The data on computed suspended sediment discharge (SD) shows a very high dispersion, skewness, and kurtosis, showing the compounded effect of Q and SC (Table 1). The range is extremely high during Spring (due to onset of agricultural activities, i.e. land preparation) and during Fall

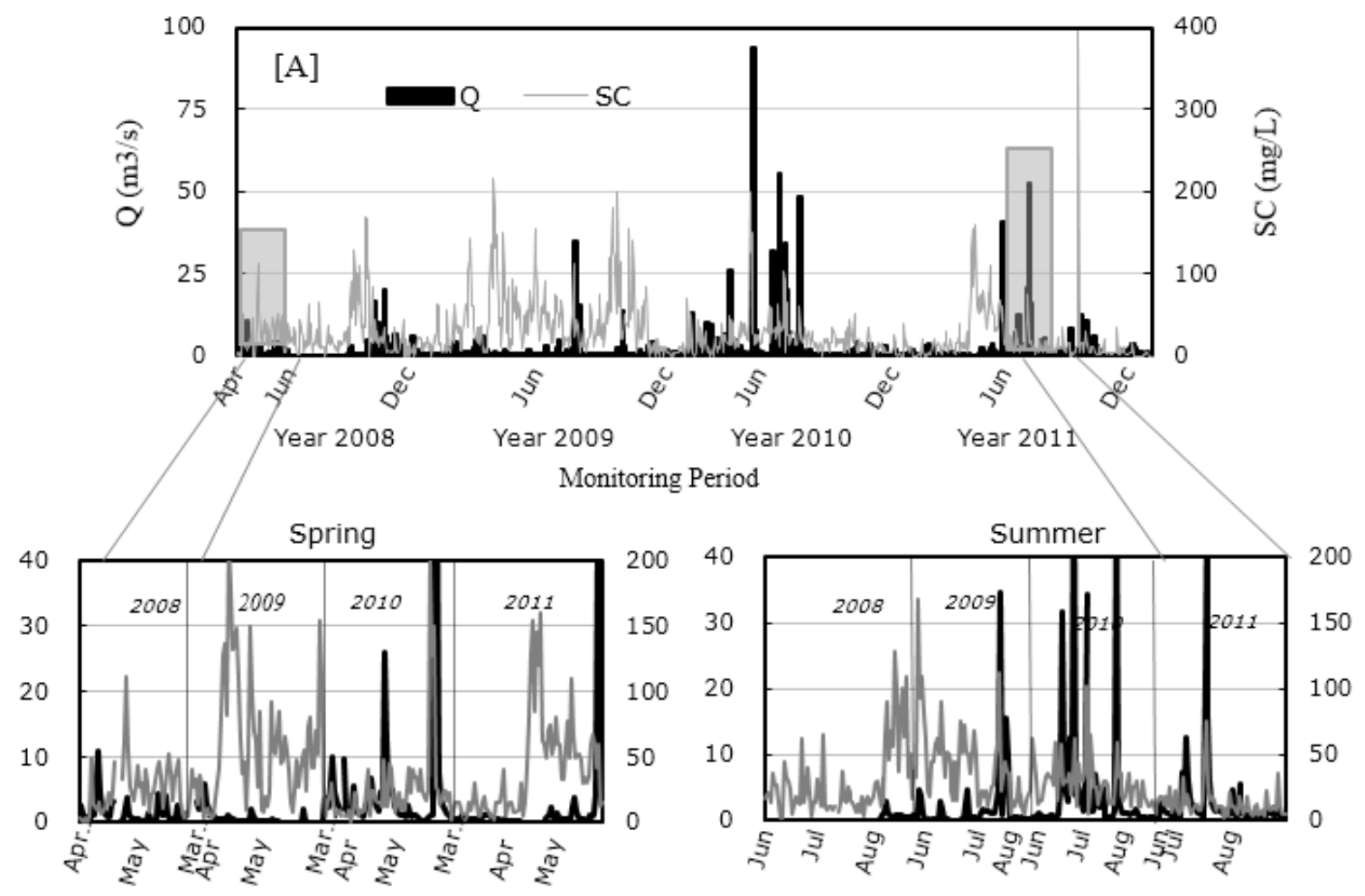

[B]

[C]

Figure 5. Time series of instantaneous discharge and sediment concentration [A] of Mima river; and highlighted portions for agricultural production season - spring [B] and summer [C] . 
(due to high storm events), while it is very low during Winter. The seasonal pattern of SD range and mean values is not consistent to that of both $\mathrm{Q}$ and SC.

The preliminary analysis using the optimum function model $\left(2^{\text {nd }}\right.$ degree polynomial) reveals very poor Q-SC correlation (Figure 6) and statistically insignificant coefficient of determination, both in aggregate $\left(\mathrm{R}^{2}=0.04\right)$ and in seasonal clusters $\left(\mathrm{R}^{2}=0.05,0.07,0.33\right.$, and 0.01$)$, making it statistically unsuitable for regression analysis. This is one of differences of small rivers from big rivers. In fact, most suspended sediment estimation studies utilized SC to derive the sediment rating curve, as it dealt with big rivers where SC has good correlation, even logarithmically transforming the values to normalized errors due to high scattering of data (Jansson, 1996; Asselman, 2000; Lenzi and Marchi, 2000; Sadeghi et. Al, 2008; $\mathrm{Hu}$ et al., 2011). In this study, the statistically significant and better correlation of Q-SD necessitates the use of suspended sediment discharge in the derivation of suspended sediment rating curve during regression analysis, hence, the model equation $S D=a Q^{b}$.

\section{Regression Analysis and Suspended Sediment Rating Curve}

The suspended sediment load was estimated by regression analysis $S D=a Q^{b}$. Regression equations for the aggregate and seasonally clustered data were derived without logarithmic transformation as $\mathrm{Q}$ values are only up to 2 degrees of magnitude, unlike previous studies involving relatively large rivers where log transformation is necessitated to standardize errors due to large range of suspended sediment values (Jansson, 1992; Sadeghi et al., 2008; Hu et al., 2011).

In order to account tfor he nil suspended sediment values and to reduce curve-fitting errors, mean loads within discharge classes or 'data stratification' were used to establish the suspended sediment rating curve. In this process, the mean values of $\mathrm{Q}$ and the corresponding mean SD of the data classes were used in the regression analysis. In the data stratification procedure, there are a total of 20 data classes using aggregate data and 14-16 data classes for the seasonally clustered data. Increasing the number of classes would not further improve the resulting regression equation, as well as its efficiency.

The suspended sediment rating curves derived as a power function using linear least squares (LLS) and non-linear least squares (NLLS) methods are shown in Figure 7. NLLS method was proposed by some investigators (Jansson, 1985; Bates and Watts, 1988) to estimate the parameters of the suspended sediment rating curve to avoid the transformation bias problem in LLS method. The fundamental difference between the two methods is in the residual term: multiplicative in LLS but additive in NLLS. According to Crawford (1991) the residual errors of the non-linear model are typically highly skewed and are not identically distributed, but the problem could be addressed by logtransformation. Nevertheless, in the present study,

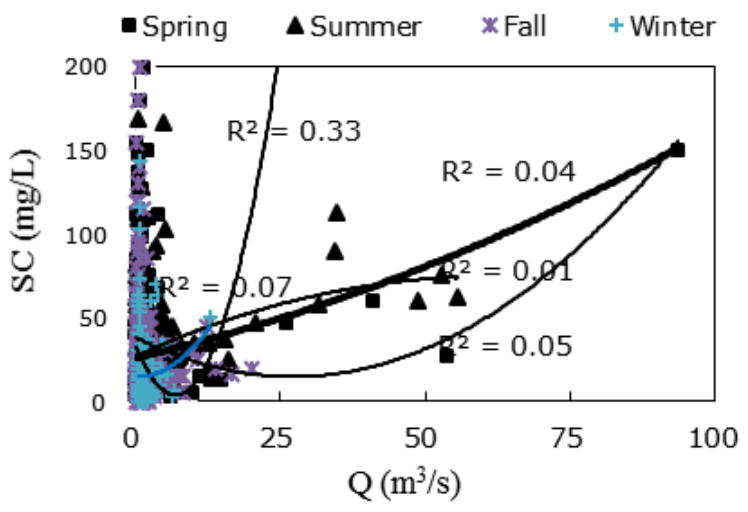

$[\mathrm{A}]$

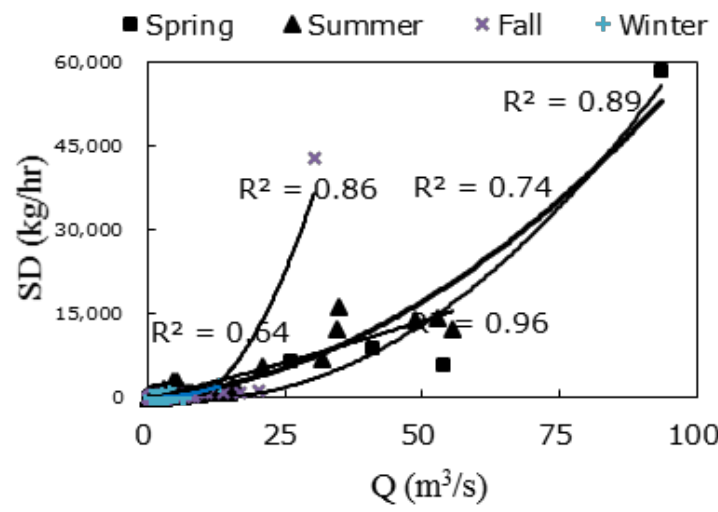

[B]

Figure 6. Correlation of discharge and suspended sediment concentration [A]; and discharge and sediment discharge $[\mathrm{B}]$ in $2^{\text {nd }}$ order polynomial regression. 


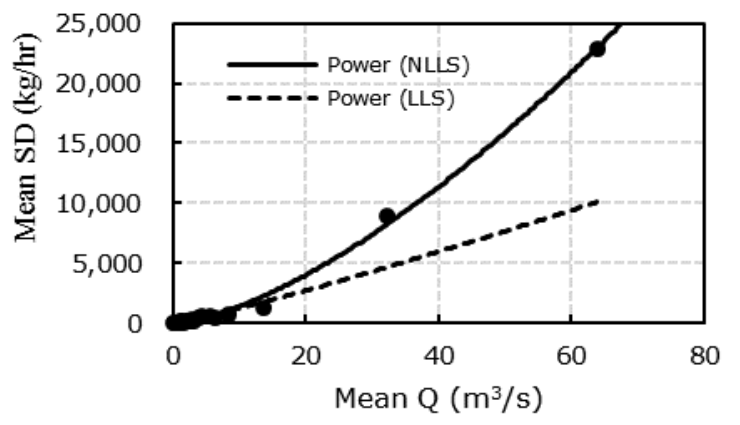

[A] Aggregate Data

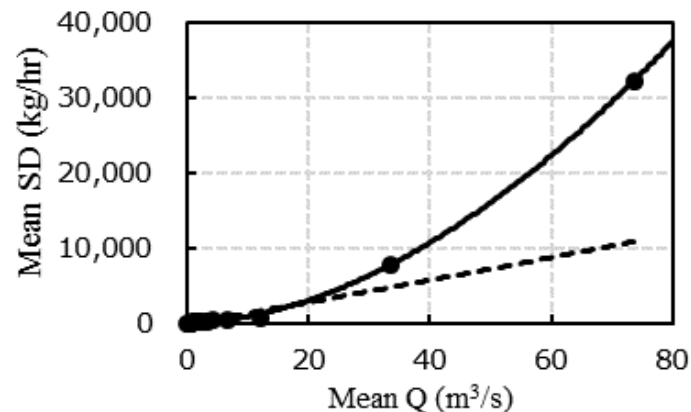

[B] Spring

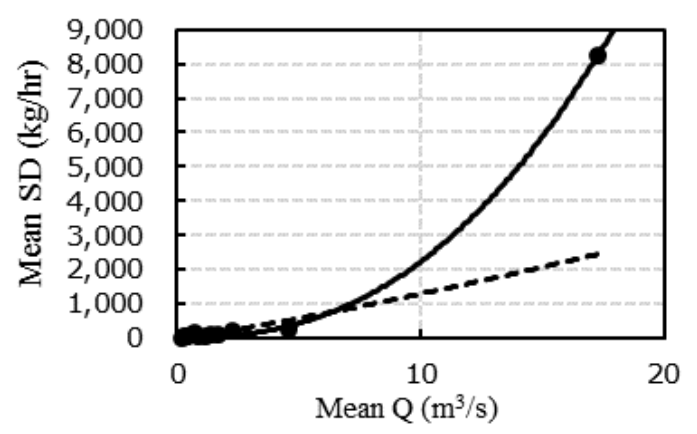

[D] Fall

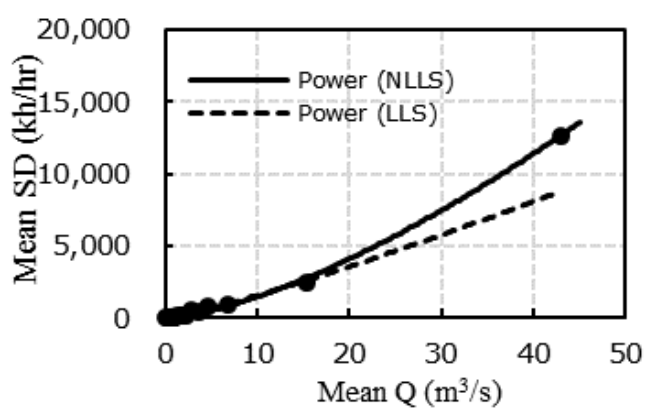

[C] Summer

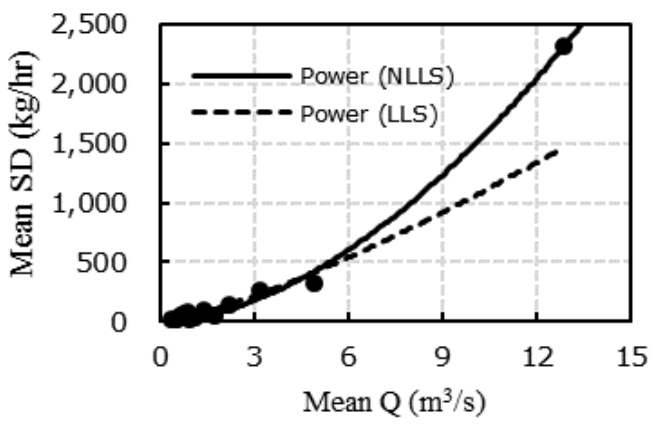

[E] Winter

Figure 7. Suspended sediment rating curves for Mima river using linear (LLS) \& non-linear least squares (NLLS) methods for aggregated data $[\mathrm{A}]$ and for different seasons - spring [B], summer [C], fall [C] and winter [E].

the curves developed using NLLS method, though not log-transformed, have a better fit than those developed by LLS method, with higher correlation and model efficiency coefficients (Table 2).

The curves developed through LLS method tended to be biased to the smaller values; hence, high values especially during storm events are not well-presented in the curve. These results in highly underestimated sediment load values. A usual correction method applied is to construct separate suspended sediment rating curves for low and high values (Jansson, 1996; Gao and Josefson, 2012) which may not anymore be necessary when apply- ing regression analysis using NLLS method. In fact, using NLLS method, an almost perfect correlation and very high efficiency coefficients could be attained when applied to mean values within discharge classes (Table 2).

The resulting regression equations are applied to all daily discharge values to determine its accuracy and efficiency for suspended sediment load estimation. Analysis revealed that NLLS method produced rating curves that estimate suspended sediment loads with highly significant accuracy, whether using aggregate or seasonally clustered data (Table 3 ). It has only $2 \sim 3 \%$ difference from 
JEEAR, Vol. 1, 2018

Table 2. Suspended sediment load equations $\left(S D=\mathrm{a} Q^{\mathrm{b}}\right)$, correlation coefficient $\left(R^{2}\right)$ and model efficiency coefficients $\left[e_{f}\right]$

\begin{tabular}{ccc}
\hline Data & LLS & NLLS \\
\hline Aggregate & $S D=91.2 Q^{1.374}(0.946)\left[-9.7 \times 10^{4}\right]$ & $S D=44.4 Q^{1.503}(0.997)[0.861]$ \\
Spring & $S D=122.3 Q^{1.043}(0.932)\left[-3.1 \times 10^{4}\right]$ & $S D=13.6 Q^{1.808}(0.999)[0.931]$ \\
Summer & $S D=103.6 Q^{1.182}(0.970)\left[-3.9 \times 10^{5}\right]$ & $S D=44.4 Q^{1.475}(0.998)[0.871]$ \\
Fall & $S D=85.2 Q^{1.177}(0.782)\left[-1.8 \times 10^{5}\right]$ & $S D=8.99 Q^{2.393}(0.999)[0.832]$ \\
Winter & $S D=51.8 Q^{1.308}(0.864)\left[-2.3 \times 10^{5}\right]$ & $S D=25.8 Q^{1.760}(0.996)[0.723]$ \\
\hline
\end{tabular}

the observed load (using annual or aggregate data) compared to $12 \sim 19 \%$ difference by LLS method. The Wilcoxon-Mann-Whitney test conducted shows that NLLS method is significantly different or significantly better than LLS method at $1 \%$ confidence level $(p=0.01)$ in terms of model efficiency coefficients, and at $5 \%$ confidence level $(p=0.05)$ in terms of correlation coefficients and estimated load (Table 4). Seasonally clustering the data also improved the sediment load estimation, though not statistically significant. For the Mima river, it improved the nearness of the estimated loads to the observed load by $1 \sim 7 \%$ using the annual data. However, it has an inconclusive effect using seasonal data.
The statistical test on significant difference (Wilconxon-Mann-Whitney) shows that aggregated and seasonally clustered data has no significant difference in terms of any parameter- $\mathrm{R}^{2}, \mathrm{e}_{\mathrm{f}}$, and SL. Comparison of the estimated suspended sediment load, both aggregate and seasonal, to the actual load also reveals no significant difference (Table 4). However, dissecting the data into LLS and NLLS methods shows that aggregated and seasonally estimated sediment load using LLS method has a significant difference from the actual sediment load, hence, statistically unacceptable; while using NLLS method results to a high p-value, indicating high acceptability.

Table 3. Estimated suspended sediment load $\left(\times 10^{4} \mathrm{~kg}\right)$ and difference from observed load $(\%)$.

\begin{tabular}{cccccc}
\hline \multirow{2}{*}{ Period } & $\begin{array}{c}\text { Observed } \\
\text { Load }\end{array}$ & Aggregate & Seasonal & Aggregate & Seasonal \\
\hline Annual & 265 & $214(-19 \%)$ & $234(-12 \%)$ & $258(-3 \%)$ & $261(-2 \%)$ \\
Spring & 88 & $64(-27 \%)$ & $70(-20 \%)$ & $85(-4 \%)$ & $74(-16 \%)$ \\
Summer & 131 & $86(-34 \%)$ & $109(-17 \%)$ & $121(-8 \%)$ & $124(-5 \%)$ \\
Fall & 28 & $38(36 \%)$ & $38(36 \%)$ & $34(21 \%)$ & $49(75 \%)$ \\
Winter & 18 & $26(44 \%)$ & $17(-6 \%)$ & $18(-1 \%)$ & $14(-22 \%)$ \\
\hline
\end{tabular}

Table 4. Wilcoxon-Mann-Whitney test $p$-values on correlation coefficient $\left(R^{2}\right)$, model efficiency coefficients $\left[e_{f}\right]$ and sediment load (SL).

\begin{tabular}{cccc}
\hline Compared Parameter & $\mathrm{R}^{2}$ & $e_{f}$ & $\mathrm{SL}$ \\
\hline LLS-NLLS & 0.06 & 0.01 & 0.05 \\
Aggregate-Seasonal & 0.67 & 0.53 & 0.36 \\
Observed-Aggregate & & & $0.22^{a}$ \\
Observed-Seasonal & & & $0.15^{b}$ \\
\hline
\end{tabular}




\section{Monthly and Seasonal Suspended Sediment Load Distribution}

The observed annual total suspended sediment load is $165 \times 10^{4} \mathrm{~kg}(2009), 471 \times 10^{4} \mathrm{~kg}$ (2010), and $159 \times 10^{4} \mathrm{~kg}(2011)$ - an annual average value of $265 \times 10^{4} \mathrm{~kg}$. On the other hand the estimated value, using rating curve developed using NLLS method on seasonally clustered data amounts to $116 \times 10^{4} \mathrm{~kg}$ (2009), $466 \times 10^{4} \mathrm{~kg}(2010)$ and $200 \times 10^{4} \mathrm{~kg}(2011)$ or an annual average of $261 \times 10^{4} \mathrm{~kg}$.

The suspended sediment load follows an erratic pattern when considered during the whole monitoring period. However, it is generally high during the April-July period and drastically low during November-January period (Figure 8). Considering the average monthly suspended sediment load values, the load started to increase in April, reaching its peak during May-July, and decreases towards December, with a slight increase during the September-October period. This pattern could be attributed to the start of land preparation during April (or middle of March), particularly in rice paddy areas; continuation of land preparation and peak of agricultural activities during May-July and occurrences of several rainfall events, some of which are torrential; and the rainy or typhoon season during September-October. However, since storm event and typhoons are not time constant, it was exhibited at least few times in any other months, i.e. Feb. 2009, Nov. 2009, Dec. 2010.

The most sediment-laden month is July, accounting $29 \%$ of the annual total suspended sediment load- with $20 \%$ of the water yield. On the other hand, June has $15 \%$ of the water yield, yet,

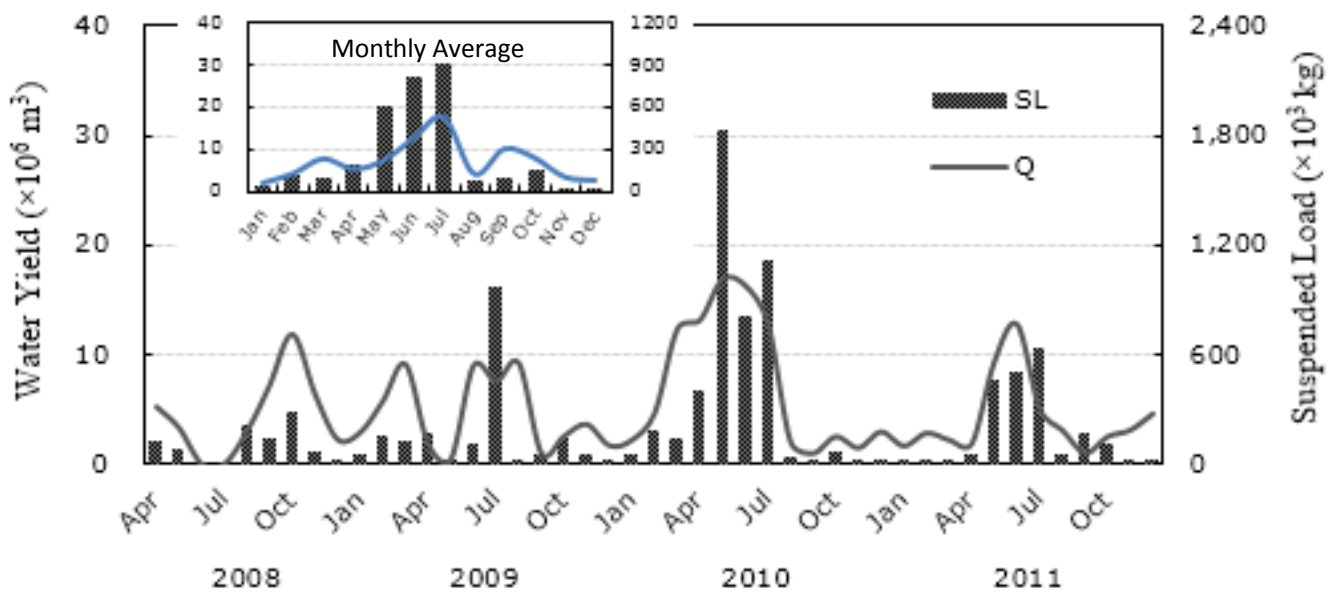

[A]

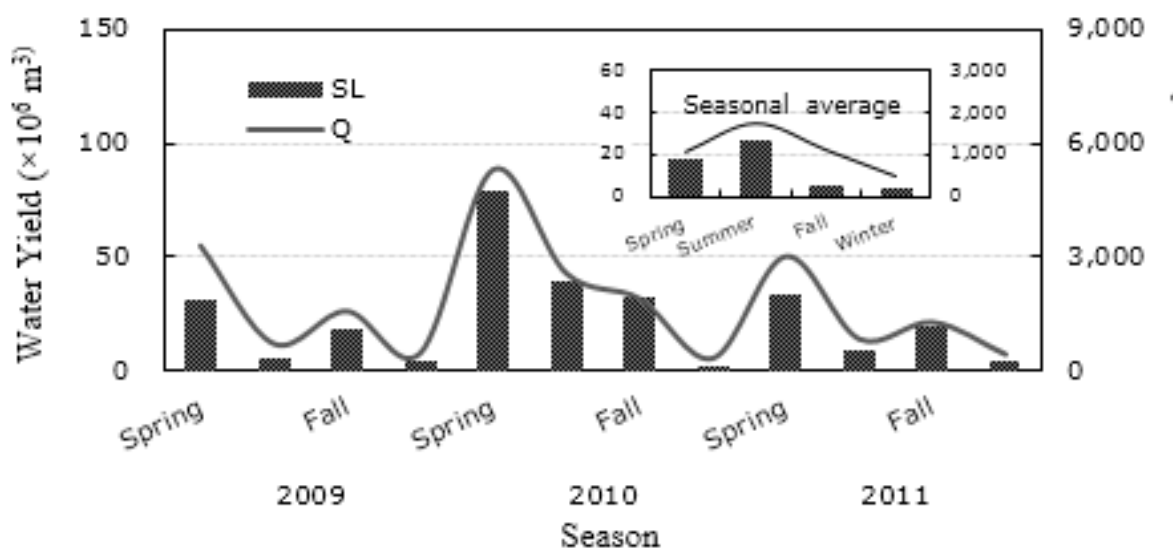

[B]

Figure 8. Seasonal suspended sediment load [A] and water yield [B] for the Year 2009-2011. 


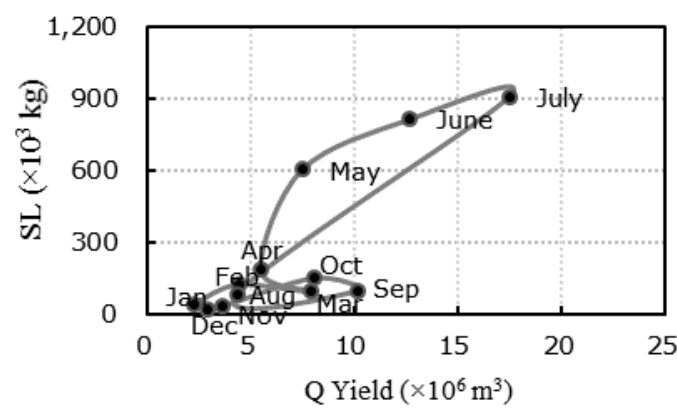

[A]

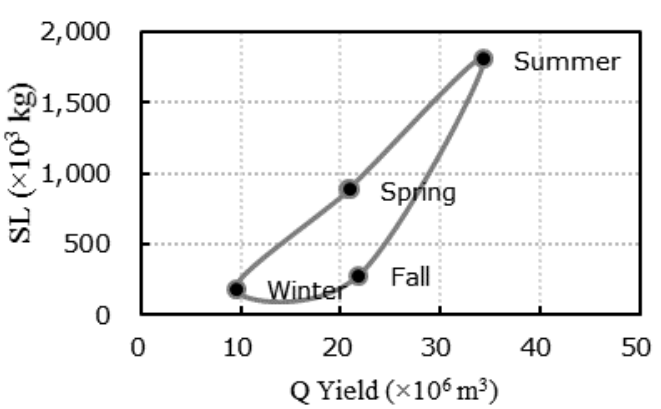

[B]

Figure 9. Monthly [A] and seasonal [B] suspended sediment load hysteresis of Mima River.

accounted for $26 \%$ of the total load. While the month of May accounted for $19 \%$ of the load, though, it has only $9 \%$ of the water yield. On the other hand, the months of December-January displayed almost the same sediment load and water yield, at 1 2\% and 3 4\%, respectively-the lowest, annually. This inequality of the water yield and suspended sediment load during peak season is highlighted on the upper part of the monthly hysteretic pattern (Figure 9).

The seasonal suspended sediment load pattern generally corresponds to that of the water yield (Figure 8 ). The factors affecting this pattern include and preparation and start of agricultural production season during Spring, agricultural production season and rainy season during Summer, end of agricultural production and rainy season during Fall, and absence of both factors during Winter.

The monthly hysteresis generally follows a counter-clockwise pattern, showing a significant increase in the suspended sediment load from April to July (Figure 9). The main attributing factors to this pattern are the rainfall events and agricultural activities, as explained earlier. The significant load increase during the period April-June reflects the increasing agricultural activities (land preparation and rice planting), as well as the effect of the rainy season. The sediment load and water yield reaches its peak on July despite decreasing agricultural activities - a manifestation of the significant effect of several episodic floods especially those occurring in the year 2010 and 2011.

While the monthly sediment load shows an erratic pattern when considered during the whole monitoring period, the seasonal sediment load pat- tern shows a rather clear clockwise cyclic pattern: high during Spring, attain its peak during Summer, decreases during Fall, and hit its lowest during Winter. Approximately half of the annual sediment load $(49 \%)$ is delivered during Summer and more than a third (33\%) during spring. This totals to $82 \%$, entailing a meager suspended sediment delivery $(18 \%)$ during the other two succeeding seasons.

\section{Conclusion}

We studied the suspended load in a small agricultural catchment with a considerable arable area apportioned to rice paddy and elucidate the discharge-suspended sediment load characteristics, establish rating curves and analyze the suspended sediment load temporal variation. As the river is small and registers nil suspended sediment during some periods, we introduced data stratification to account for the nil values and to improve the regression. We also developed the suspended sediment rating curve, as a power equation model, using least (LLS) and non-linear least squares (NLLS) methods, applying it to the aggregated and seasonally clustered data.

Results and analysis on the developed suspended sediment rating curves shows that NLLS method is more appropriate for small rivers, especially one having relatively wide range of discharge. The method produces rating curves which have higher model and estimation efficiencies, resulting to estimated loads which are closer and not significantly different from the observed load. Seasonally clustering the data also results to better sediment rating curves but the difference, as of model efficiency and estimated load, is not statistically 
significant.

The temporal distribution and variability of the sediment load appears to be mainly related to two major factors: rainfall and agricultural activities. The agricultural activities apparently affect the suspended sediment load during Spring, the agricultural activities and rainfall during Summer, the rainfall during Fall, and the absence of both during Winter. The data results of imply significant impact of seasonal land use in the area and the degree of cultivation in its agricultural area.

\section{Acknowledgment}

This study was supported and partially funded by the Nan-yo Regional Office of Ehime Prefecture government, Japan. The authors would also like to thank the Kihoku Town office (Ehime Prefecture) and Nishitosa branch office, Shimanto City (Kochi prefecture) for the valuable support in the field observation and data gathering.

\section{References}

Achite, M. and Ouillon, S. (2007). Suspended sediment transport in a semiarid watershed, Wadi Abd, Algeria (1973-1995). Journal of Hydrology 343: 187-202.

Asselman, N.E.M. (2000). Fitting and interpretation of sediment rating curves. Journal of Hydrology 234: 228-248.

APHA-American Public Health Association. (1995). Standard methods for the examination of water and wastewater, pp. 2540-2550.

Bates, D.M., Watts, D.G. (1988). Nonlinear Regression Analysis and its Application. Wiley, New York, $365 \mathrm{p}$..

Batalla, R.J., Sala, M.. (1994). Temporal variability of suspended sediment transport in a Mediterranean sandy gravel-bed river. IAHS Proceedings No. 224, pp. 299-305.

Cordova, J.R., Gonzalez, M. (1997). Sediment yield estimation in small watersheds based on streamflow and suspended sediment discharge measurements. Soil Technology 11, 57-65.

Crawford, C.G. (1991). Estimation of suspendedsediment rating curves and mean suspendedsediment loads. Journal of Hydrology 129: 331-
348.

De Vries, A., Klavers, H.C. (1994). Riverine fluxes of pollutants: monitoring strategy first, calculation methods second. European Journal of Water Pollution Control 4, pp. 12-17.

Ferguson, R.I. (1986). River loads underestimated by rating curves. Water Resources Research Journal 22(1):74-76.

Gao, P., Josefson, M. (2012). Temporal variations of suspended sediment transport in Oneida Creek watershed, central New York. Journal of Hydrology 426-427, pp.17-27.

Hasnain, S.I. (1996). Factors controlling suspended sediment transport in Himalaya glacier meltwaters. Journal of Hydrology 181, 49-62.

Horowitz, A.J. (2003). An evaluation of sediment rating curves for estimating suspended sediment concentrations for subsequent flux calculation. $\mathrm{Hy}$ drological Processes 17, pp. 3387-3409.

Hu, B., Wang, H., Yang, Z., Sun, X. (2011). Temporal and spatial variations of sediment rating curves in the Changjiang (Yangtze River) basin and their implications. Quaternary International 230, 34-43.

Iadanza, C., Napolitano, F. (2006). Sediment transport time series in the Tiber River. Physics and Chemistry of the Earth. 31, 1212-1227.

Jansson, M.B. (1985). A comparison of detransformed logarithmic regressions and power function regressions. Geografika Annaler. 67A(1-2):61-70.

Jansson, M.B. (1992). Suspended sediment inflow to the Cachi reservoir. In: Sedimentological Studies in the Cachi Reservoir, Costa Rica. UNGI Rep. 81, Department of Physical Geography, Uppsala University, Uppsala, Sweden, pp. 41-77.

Jansson, M.B. (1996). Estimating a sediment rating curve of the Reventazon River at Palomo using logged mean loads within discharge classes. Journal of Hydrology, 183, 227-241.

Lana-Renault, N., Regues, D., Marti-Bono, C., Begueria, S., Latron, J., Nadal E., Serrano P., Garcia-Ruiz, J.M. (2007). Temporal variability in the relationship s between precipitation, discharge and 
suspended sediment concentration in a small Mediterranean mountain catchment. Nordic Hydrology $38(2), 139-150$.

Lenzi, M., Marchi, L. (2000). Suspended sediment load during floods in a small stream of Dolomites (Northeastern Italy). Catena 39, 267-282.

Maidment, D.R. (1992). Handbook of Hydrology. McGraw-Hill, 347p.

Mendicino, G. (1999). Sensitivity analysis on GIS procedures for the estimation of soil erosion risk. Natural Hazards 20: 231-253

Meybeck, M., Friedrich, G., Thomas, R., Chapman, D. (1996). Rivers. In: Water Quality AssessmentsA Guide to Use of Biota, Sediments and Water in Environmental Monitoring, $2^{\text {nd }}$ Edition, UNESCO/ WHO/UNEP, pp. 1-79.

Nash, J.E., Sutcliffe, J.V. (1970). River flow forecasting through conceptual models. Part I. A discussion of principles. Journal of Hydrology 10, 282 -290 .

Post, D.A., Jakeman, A.J. (1996). Relationship between catchment attributes and hydrological response characteristics in small Australian mountain ash catchments. Hydrological Processes 10, pp. 877-892.

Restrepo, J.D., Kjerfve, B. (2000). Magdalena river: inter-annual variability (1975-1995) and revised water discharge and sediment load estimates. Journal of Hydrology 23, 137-149.

Sadeghi, S.H.R., Mizuyama, T., Miyata, S., Gomi, T., Kosugi, K., Fukushima, T., Mizugaki, S., Onda, Y. (2008). Determinat factors of sediments graphs and rating loops in a forested watershed. Journal of Hydrology 356, 271-282.

Shanahan, P., Henze, M., Koncsos, L., Rauch, W., Reichart, P, Somlyody, L., Vanrolleghem, P. (1998). River water quality modeling II- Problems of the art. Wat. Sci. Tech., 38, pp. 245-252.

Thomas, R.B. (1985). Measuring suspended sediment in small mountain streams. In: General Technical Report PSW-83, USDA Forest and Range Experimental Station, 105p.

Walling, D.E. (1983). The sediment delivery prob- lem. Journal of Hydrology 65, 209-237.

Walling, D.E., Webb, B.W. (1981). The reliability of suspended sediment load data. IAHS Publications, 133, 177-194.

Walling, D.E., Webb, B.W. (1992). Water Quality: Physical Characteristics. In: The Rivers Handbook, Volume 1. Blackwell Scientific Publications, Oxford, England, 48-57. 